\title{
INTERPRETATION OF MATHEMATICAL MODEL OF MEASUREMENT OF A PUBLIC WORK COST AFTER CONTRACTOR SELECTION AND BEFORE THE START OF CONTRACTUAL ACTIVITIES
}

\author{
Pavlos METALLINOS \\ School of Science and Technology, Patra, Greece \\ Hellenic Open University, Patra, Greece \\ Corresponding author's email: kpaulosm@gmail.com
}

\begin{abstract}
The manuscript focuses on the situation before the execution of construction activities starting and after the crystallization of the contractual object between Public Authority and contractor. The aim of the article is to investigate the interpretation of mathematical model of measurement of a public work cost after contractor's selection and before the start of contractual activities. Our study results have been drawn through the interpretation of equations, which have been extracted by the study of the multiparameter polynomial, as these have been developed and proven in the study "Measurement of the Cost of a Public Works Project: The Case of Greece". Taking advantage of the mathematical model, which was defined in the previous study, we develop the comprehension of critical conditions, which determine finally the equivalent in money of cost of each technical commodity for the purchaser and shape the execution conditions of competition in the construction market. Due to the relation of Hellenic legislation with that of EU, the suggested mathematical cost measurement model of a public work and the conclusions of the present article can be used in further study related to a critical evaluation between Earned Value Management Method and Earned Schedule Method. Despite the Hellenic experience, the approach of cognitive object and the conclusions which are reached could be applied in the international practice, if we take into consideration that the process of contractor's selection that is used at least in the European Union, is similar.
\end{abstract}

Keywords: Cost, earned schedule method, earned value method, public works.

\section{INTRODUCTION}

In the study "Measurement of the Cost of a Public Works Project: The Case of Greece" it has been proven that the Hellenic public work's equivalent in money is attributed by the relation:

$$
Y_{+}=x+\Omega_{x 1}=x^{\prime}{ }_{1}+x^{\prime \prime}+\Omega_{x 1}
$$

or 


$$
Y_{+}=\left(X+\Omega_{x 1}\right)-X_{2}
$$

where

$\Omega_{x 1}$ - one of the components of the project $X_{1}$ before the auction is a finite, arbitrary quantity to the value of $\Omega$, whose purpose is to facilitate the revision and updating (deflating) of the prices of Articles (activity description texts) in the Invoice of Tender Documents, in such a way that the individual values of the works remain stable and deflated. Due to the auction, $\Omega$ is reduced by the contractor's discount $x_{1}: \Omega_{x 1}$;

$x^{\prime}{ }_{1}$ - the difference between the contractual exchange value $\left(X^{\mathrm{d}}{ }_{1}=X_{1}-x_{1}\right)$ and the demanded exchange value $\left(X_{2}\right)$ by the contractor if the buyer were not a public authority but some private citizen: $X^{\mathrm{d}}{ }_{1}-X_{2}=x^{\prime}{ }_{1}$

$X$ - the difference between the final cost of the project $X$ and $X_{2}: X-X_{2}=x ; X$ can be specified accurately only after the conclusion of the construction process and the handing over of the project to its users. For that reason, this can be different from $X^{\mathrm{d}}{ }_{1}$;

$x^{\prime \prime}-$ the difference between $X$ and $X^{\mathrm{d}}{ }_{1}: X-X^{\mathrm{d}}{ }_{1}=x^{\prime \prime}$.

According to the above-mentioned considerations, the price of each Hellenic Public Agent's specific technical infrastructure has a cost equal to what a private individual $\left(X_{2}\right)$ would pay, if he were its purchaser, augmented according to the price of parameter $Y_{+}$.

Taking it for granted, we focus on the situation before the execution start of construction activities and after the crystallization of the contractual object between Public Authority and contractor.

We take into consideration that in the European Union, the selection processes of a contractor, are similar. They are defined by Communication "Europe $2020-\mathrm{A}$ Strategy for Smart, Sustainable and Inclusive Growth", [COM (2010) 2020 final], Directive 2014/23/EU (L94) on the Award of Concession Contracts, Directive 2014/24/EU/(L94) on Public Procurement and Repealing Directive 2004/18/EC \& Directive 2014/25/EU (L94) on Procurement by Entities Operating in the Water, Energy, Transport and Postal Services Sectors and Repealing Directive 2004/17/EC and Hellenic Law 4412/2016 "Public Contracts of Projects, Procurements and Services (adaptation to Directives 2014/24/EU and 2014/25/EU)". As a result, the method of approach of cognitive object and the reached conclusions find more general application in the international practice.

Thus, immediately after the contractor's selection and prior to the commencement of construction activities, the profile of the technical project is ultimately determined exclusively by the pair of variables $\left(X^{\mathrm{d}}{ }_{1}, T_{2}\right)$ :

$$
\left(X^{\mathrm{d}}{ }_{1}, T_{2}\right)=\left(\left\{\left[X^{*}+(C . P .)+\text { taxes }\right]-x_{1}\right\}, T_{2}\right)=\left(\left[X_{1}-x_{1}\right], T_{2}\right)
$$

where

$$
X_{2} \leq X^{\mathrm{d}}{ }_{1} \leq X_{1}
$$


and

$X^{*}$ - the financial price of the budgeted individual Article activities of the Tender Documentation. Their difference is equal to the sum of contractor's legislated rate of profit (C.P.) plus the legislated rate of contingencies and taxes: $X_{1}$ $-X^{*}=(C . P)+$. taxes.

It results from condition (4) that at the planning stage, the construction conditions of a project $\left(X_{1}^{\mathrm{d}}, T_{2}\right)$ are attributed in the following way:

1) $T_{2} \leq T^{\prime}{ }_{1} \rightarrow T_{2}=T^{\prime}{ }_{1}-t^{\prime}{ }_{1} \rightarrow$

$$
\begin{aligned}
& T_{2} \leq T^{\prime}{ }_{1} \rightarrow T_{2}=T^{\prime}{ }_{1}-t^{\prime}{ }_{1} \rightarrow \\
& X_{2}=X^{\mathrm{d}_{1}}{ }_{1}-x^{\prime}{ }_{1} \rightarrow X^{\mathrm{d}}{ }_{1}=X_{2}+x^{\prime}{ }_{1}:
\end{aligned} \quad\left\{\begin{array}{l}
x^{\prime}{ }_{1}=0 \rightarrow X^{\mathrm{d}}{ }_{1}=X_{2} ; \\
x^{\prime}{ }_{1} \neq 0 \rightarrow X^{\mathrm{d}_{1}}=X_{2}+x^{\prime}{ }_{1}
\end{array}\right.
$$

2) $X^{\mathrm{d}}{ }_{1} \leq X_{1} \rightarrow$



where

$T_{2}$ - the necessary period of time $(T)$ for construction of the technical commodities in question. The compiler of the technical design study is required to estimate them on the basis of his experience and judgment. This process includes the obligations he undertakes as producer of the "technical design study". The specialist in question, taking into account the progress of technology, the specific characteristics of the project and present-day methods of organisation and functioning of construction sites, proposes a time period $T_{2}$. Mostly $T_{2}$ is less than $T_{1}$ because these factors cannot be defined using the Price Analysis;

$T^{\prime}{ }_{1}$ - the necessary period of time $(T)$ for construction of the technical commodities in question, if the individual contractual activities were being executed as the description of the Ministry's Invoice orders, according to the contractor's productivity, technical distribution of work, know-how etc.;

$t^{\prime}{ }_{1}-$ the difference between $T^{\prime}{ }_{1}$ and $T_{2}: t^{\prime}{ }_{1}=T^{\prime}{ }_{1}-T_{2}$.

\section{STUDY OF MODEL $X_{1}=\left[X^{*}+(\right.$ C.P. $)+$ taxes $]$}

\subsection{Case of equation of Tender Documentation price with medium social price, which the former would have if it were constructed for a private individual: $X_{1}=X_{2}$}

Conditions:

$$
\begin{aligned}
\left(x_{1}, x^{\prime}{ }_{1}\right)=(0,0) \rightarrow X_{1}=X_{2} \quad: \quad X_{1}=\left[X^{*}+(C . P .)+\text { taxes }\right] & \\
& X^{\mathrm{d}_{1}}=X_{2}+x^{\prime}{ }_{1} ; \\
& X_{1}=X^{\mathrm{d}_{1}}+x_{1} .
\end{aligned}
$$

The Tender Documentation price is equal to the medium social price, which the former would have if it were constructed for a private individual: 


$$
X_{1}=X_{2} \text {. }
$$

With replacement of terms of our affair in (8), we have:

$$
X^{*}+(C . P .)+\text { taxes }=X_{2}^{*}+(C . P .)_{2}+(\text { taxes })_{2} .
$$

We rewrite (9) and solve it in terms of (C.P.) $)_{2}$ :

$$
\begin{aligned}
& X^{*}+\left[X^{*} \cdot(C . P .)\right]+\text { taxes }=X_{2}^{*}+\left[X^{*}{ }_{2} \cdot(C . P .)_{2}\right]+(\text { taxes })_{2} \rightarrow \\
& X^{*} \cdot[1+(C . P .)]+\text { taxes } \cdot\left\{X^{*} \cdot[1+(C . P .)]\right\}=X_{2}^{*} \cdot\left[1+(C . P .)_{2}\right]+\text { taxes } \cdot \\
& \cdot\left\{X_{2}^{*} \cdot\left[1+(C . P .)_{2}\right]\right\} \rightarrow \\
& \left\{X^{*} \cdot[1+(C . P .)]\right\} \cdot(1+\text { taxes })=\left\{X_{2}^{*} \cdot\left[1+(C . P .)_{2}\right]\right\} \cdot(1+\text { taxes }) \rightarrow \\
& \left\{X^{*} \cdot[1+(C . P .)]\right\}=\left\{X_{2}^{*} \cdot\left[1+(C . P .)_{2}\right]\right\} \rightarrow \\
& (\text { C.P. })_{2}=\underline{X^{*} \cdot[1+(\text { C.P. })]}-1 \text {. } \\
& X_{2}^{*}
\end{aligned}
$$

Given the enacted algebraic price of (C.P.), we conclude from (10) that the more the algebraic price of numerator is augmented the more the Article (activity description texts) prices (which are included in the contractual Invoice) are divergent upwards from the corresponding prices $\left(X_{2}^{*}\right)$ of construction market and vice versa.

With the subscription of condition (10), in case (8) we conclude that the project construction by the producer in exchange for the equivalent in money

$\left[X^{*}+(C . P)+\right.$. taxes $]$ leads to the following situations, according to his contractual obligations.

If $(C . P)=.(C . P .)_{2}$, then the prices of Articles (activity description texts) of the contractual Invoice $\left(X^{*}\right)$ are equal to the market prices $\left(X_{2}^{*}\right)$ of the corresponding works.

$$
X^{*}=X^{*}
$$

Proof:

$$
\begin{gathered}
(C . P .)=\frac{X^{*} \cdot[1+(C . P .)]}{X^{*}{ }_{2}}-1 \rightarrow \\
\left.X_{2}^{*} \cdot(C . P .)=X^{*}+\left[X^{*} \cdot(C . P .)\right]\right\}-X_{2}^{*} \rightarrow \\
\left(X^{*}-X_{2}^{*}\right)+(C . P .) \cdot\left(X^{*}-X_{2}^{*}\right)=0 \rightarrow \\
\left(X^{*}-X_{2}^{*}\right) \cdot[1+(C . P .)]=0 \rightarrow \\
X^{*}=X_{2}^{*} .
\end{gathered}
$$

- If $(C . P)>.(C . P .)_{2}$, then the prices of Articles (activity description texts) of contractual Invoice $\left(\mathrm{X}^{*}\right)$ are smaller by those of construction market $\left(X^{*}{ }_{2}\right)$. 
- If $($ C.P. $)<(C . P .)_{2}$, then the prices of Articles (activity description texts) of contractual Invoice $\left(X^{*}\right)$ are bigger by those of construction market $\left(X_{2}^{*}\right)$.

As a rule, the first two cases are not addressed in the construction market (Metallinos, 2011, p. 72). The experience has proven that seldom Article (activity description texts) individual prices of Ministry's Price Analysis or Ministry's Standard Item Lists are smaller or equal to works' prices of corresponding technologies, which are executed for the construction of private projects. For the most part, in general, those are bigger by market correspondent prices either they were involved in Price Analysis mainly or they were involved in Standard Item Lists. Consequently, for the most part the last case constitutes to the most likely scenario.

Moreover, it is concluded that if producer's legislated and precisely determined rate of profit is smaller by social mean $\left[(C . P)<.(C . P .)_{2}\right]$ then in order to tender in the auction, with the prospect to contract in, an additional profit should be ensured to him a priori by the legislator-purchaser in general, in order to their sum be equal at least with the profit social mean $\kappa$ (where $\left.\kappa \in X_{2}\right)$ of the Private Sector Technical Projects. Thus, under the condition that $\kappa$ is apportioned into necessary equivalent for the reproduction of himself and his family and in capital, which he is going to accumulate for the reproduction of his enterprise, if we have:

$$
X_{2}=X_{2}^{*}+X_{2}^{*} \cdot(C . P .)_{2}+\text { taxes }=X_{2}^{*}+\kappa+\text { taxes }
$$

then, taking into consideration (8), at least it should be in effect:

$$
\kappa=X^{*} \cdot(E . O .)+\mathrm{d} \kappa .
$$

Besides, especially, during the period of Prices Analysis application (up to 2004) and later also, the random producer could appropriate a net profit in money over $\kappa$ (where $\kappa \in X_{2}$ ). According to equation (10) in (Metallinos, 2012), it results in:

$$
\begin{gathered}
Y_{+}=x+\Omega_{x 1}=x^{\prime}{ }_{1}+x^{\prime \prime}+\Omega_{x 1} \\
\text { or } \\
Y_{+}=\left(X+\Omega_{x 1}\right)-X_{2} .
\end{gathered}
$$

[above numbered as (2)]

In conclusion, we understand that data of the third version $\left[(E . O)<.(E . O .)_{2}\right]$ impose:

where

$$
\mathrm{d} \kappa=f\left(Y_{+}\right)
$$

$$
\mathrm{d} \kappa \in\left(0, Y_{+}\right]
$$

in order to make constructors declare their willingness to undertake the execution of production works of public works' project, by taking part in auction. The financial benefit of $Y_{+}$, which is mostly gained by public works contractors, corresponds to such an algebraic price of an equivalent in money so that it is proven that $\mathrm{d} \kappa$ value deficit is coverable. Furthermore, $\left(Y_{+}-\mathrm{d} \kappa\right)$ corresponds to a contractual profit, which assures the merchant-seller a profit that would not be 
appropriated if a particular project were constructed on behalf of a private individual rather than the state (Metallinos, 2012). Even afterwards the application of Standard Item Lists, $Y_{+}$continues as value quantity in money, which is collected by contractor over $\kappa$, although its algebraic size has decreased because of corresponding reduction of prices of those Articles (activity description texts), in comparison with Price Analysis Articles (Metallinos, 2011, p. 72).

It is mentioned that in this case we supposed that $x^{\prime}{ }_{1}=0$. For that reason, it is concluded that if construction works are executed according to the time schedule $\left(\Omega_{x 1}=\Omega=0\right)$ and/or there is no additional contract $\left(x^{\prime \prime}=0\right)$, then, according to equation (10) in (Metallinos, 2012):

$$
Y_{+}=0 .
$$

On the contrary, if it were $Y_{+} \neq 0$ (because $\Omega \neq 0$ and/or $x^{\prime \prime} \neq 0$ ), this would be added as surplus (additional profit) on $\kappa$ (where $\kappa \in X_{2}$ ), according to (Metallinos, 2012) equation (10).

We come back to the above-mentioned necessary guarantee of an additional rate of profit, over (C.P.), with the purpose of participation motivation be given to the candidate contractor.

The use value of each technical project is not changed; it is constructed on behalf of a private individual or on behalf of a public agent. Of course, in both cases, the contractor aspires to appropriate the branch mean rate of profit, at least. In the period of Price Analysis enforcement, a contractor could appropriate this return in money over the (C.P.) by applying higher productivity process than the one, which was described in the main text of Articles (activity description texts), which had been included in the Invoice of Auction Copies $\left(T_{2}<T_{1}\right)$. Conclusion is obvious because the mentioned and described technology in the Price Analysis, the technical distribution of work etc. (conditions that determine the degree of productivity) corresponded to the mean social sizes which these had at the enactment of themselves in the 1960s and 1970s, without keeping up to date in the following years up to 2004, according to the development and the progress of engineering science and construction project management. Thus, a contractor even if he could not construct his technical commodity with larger degree of productivity than social mean of the latter economic period, he was appropriating surplus (additional) profit as he used larger degree of productivity in any case, from what it was determined in the Ministry's Invoices.

The algebraic price of particular surplus (additional) profit increased along with an increase in time distance of activity execution of the project from the enactment date of particular Articles (activity description texts) of Price Analysis. Consequently, according to the data, a contractor could acquire even more rate of profit than social mean. This datum was not caused by the process of cost accounting of individual Articles (activity description texts) but because of enacted (via the Articles) technology, technical distribution of work and productivity finally (Metallinos, 2011, ch. 2, ch. 3).

In any case, according to the contractual terms the contractor was committed to hand over the project to its users at the end of period $T_{2}$. $T_{2}$ had been determined approximately by the producer of this particular ideal technical commodity, i.e., the 
technical design study. After approval of the tender documents by the Public Authority (i.e. the Purchaser of Technical Design), this time period corresponded to average social working time. Because individual activities (individual technical products) corresponded to articles (activity descriptions) of Prices Analysis, these corresponded to old-fashioned technology, old way division of labour, previous standards, etc. Thus, manufacturers were able either to document overrun T2 or execute activities which were not included in the contractual Invoice.

Let us come back to our initial supposition, where $x_{1}^{\prime}{ }_{1}=0$. According to the above-mentioned considerations, it is shown that in no case this could annihilate the difference of productivity degrees (expressed in money) among enacted technology, technical distribution of work etc. and applied technology, executed technical distribution of work etc. The reason is focused on how the collective capitalist structured the Articles (activity description texts) of Price Analysis.

To be exact, parameter $x^{\prime}{ }_{1}$ corresponds to the difference between contractual price $X^{\mathrm{d}}{ }_{1}$ and project value in money $X_{2}$ if this were private. It is concluded that the variation of $x^{\prime} 1$ was not shaped exclusively by technology, distribution of work etc. which were included in the main text of each Article of contractual Copy Invoice, but arbitrarily by the exterior factor "collective capitalist". During the total period of Price Analysis enforcement, the description part of Article (activity description text) and the algebraic price of productive indicator analysis remained immutable as a rule. On the contrary, the unit price of each Article was revised. Contractor was modifying the Article prices of Price Analysis in total. On the other hand, he maintained immutable all other structural factors of Ministry's Invoice Articles (activity description texts), which participated in the determination of the abovementioned algebraic price, according to the theory of Functional Analysis (Metallinos, 2011, ch. 2). He continued functioning the same way despite the replacement of Price Analysis from Standard Item Lists (Metallinos, 2011, p. 72).

Recapping consequently, we come to a final conclusion. Objectively and according to the experience of public works' projects $x^{\prime}{ }_{1}$ is not able to be equal to zero.

Even if between private and public projects the equivalent in money for the purchase execution of each individual necessary activity were equated, it would result as a rule that contractor's technical distribution of work (at least this one) and his work productivity also would ensure to him the appropriation of $x^{\prime}{ }_{1}$, in the case of a public works' project. This would be due to reproduction of historical crystallized conditions of public works' contracting capital and due to total circulation of historical crystallized process of capitalized relation technical terms. Consequently, the initial condition of the case we study is inept finally, and it can be concluded that even if $x_{1}=0$, it will always be in effect $X_{1} \neq X_{2}$, since as a rule they will differ at $x^{\prime}{ }_{1}$. Even if the algebraic price of $T_{2}$ is confirmed and $\Omega_{x 1}=0$, despite $T_{2}$ is an estimated determined size. This is the reason, why in any case auction winner will appropriate over $\kappa$ an additional profit $Y_{+}=x^{\prime}{ }_{1}$, without its equivalent value being incorporated in construction cost of technical commodity.

We can conclude that the range of prices of parameter $Y_{+}$oscillates between $x^{\prime}{ }_{1}$ and $x+\Omega_{x 1}$ :

$$
Y_{+} \in\left[x_{1}^{\prime},\left(x+\Omega_{x 1}\right)\right]
$$




\subsection{Case of Tender Documentation budget equation of a public project with the mean social for private ones, increased by the discount price of bidder: $X_{1}=X_{2}+x_{1}$}

Conditions:

$$
\begin{aligned}
\left(x_{1}, x^{\prime}{ }_{1}\right)=\left(x_{1}, 0\right) \rightarrow X_{1}=X_{2}+x_{1}: \quad & X_{1}=\left[X^{*}+(\text { C.P. })+\text { taxes }\right] \\
& X^{\mathrm{d}}{ }_{1}=X_{2}+x^{\prime}{ }_{1} ; \\
& X_{1}=X^{\mathrm{d}}{ }_{1}+x_{1} .
\end{aligned}
$$

The case study requires the rewording of equation:

$$
\begin{array}{ll}
\left(x_{1}, x^{\prime}{ }_{1}\right)=\left(x_{1}, 0\right) \rightarrow X_{1}=X_{2}+x_{1} \rightarrow: & X_{1}=\left[X^{*}+(\text { C.P. })+\text { taxes }\right] ; \\
X_{1}=X_{2}+x_{1} * \cdot X_{1} & X^{\mathrm{d}_{1}}=X_{2}+\left(x^{\prime}{ }_{1} * X^{\mathrm{d}}{ }_{1}\right) ; \\
& X_{1}=X^{\mathrm{d}}{ }_{1}+\left(x_{1} * \cdot X_{1}\right) .
\end{array}
$$

In theory, the price range of parameter $x_{1}$ is included in open space $(0,1)$, in the case where we do not refer to negative discounts. Of course, even in this case, if $x_{1}$ oscillates inside $\left[(C . P .)_{2}, 1\right)\left\{:\left[(C . P .)_{2} \in(-\infty, 0)\right\}\right]$, because we report in algebraic prices near zero (where $\lim _{x_{1} \rightarrow 0^{-}} x_{1}=\mathrm{d} x$ ) (Metallinos, 2011, ch. 3), analysis conclusions remain the same.

It is obvious that as it results from the conclusions of previous (1st) case, the price of $x^{\prime}{ }_{1}=X^{\mathrm{d}}{ }_{1}-X_{2}$ cannot equal zero, as a rule. If $x_{1} \in(0,1)$ is increased from zero to one, this results in a decrease in the price equivalent in money of contractual object concerning the corresponding price, which was calculated by the author of Auction Copies firstly:

$$
X^{\mathrm{d}}{ }_{1}=\left(1-x_{1}\right) \cdot X_{1}
$$

If a candidate contractor offers a particular discount price in order to a specific project construction be assigned to him it follows that the discount biggest price equals the biggest quantity of relative surplus value, which can be appropriated by this merchant-producer because of his productivity, his work's technical distribution, his know-how etc. However, it is possible because of an incorrect crisis, or as a result of the competition which is held in the market of public work's projects among contractors, a candidate can submit bigger discount price $\mathrm{x}_{1}$ than that which he can substitute with relative surplus value. In this case, it is obvious that his individual capital is going to be able to correspond to his contractual obligations only if he is able to cure his foul via $Y_{+}$, an extra profit additional to $\kappa$ 
$\left(\kappa \in X_{2}\right)$ (Metallinos, 2011). In our case, particular equivalent corresponds to price $x^{\prime}{ }_{1}$.

Consequently, as candidate capital offer is approaching its critical price (max $x_{1}$ ), the pressure is much more powerful against its competitors with the view of abandoning the sector of public works and limiting their entrepreneurship in the production of private works. Of course, in order to achieve this goal, it is presupposed to ensure conditions, which were mentioned before, relatively with productivity, technical distribution of work, know-how etc.

Hence, the abrogation of the use of mathematical method (Law 2576/98) for contractor's selection, the simultaneous replacement of Price Analysis from Standard Item Lists and the modification of article $4 \S 2$ of Law 4694/1930 by Law $3263 / 2004$, and the enactment of Law 2940/2001 confirm the existence of a strategic policy on behalf of the collective capitalist (Metallinos, 2013a). Candidate contractors were obliged to submit offers, which tended to algebraic price $X_{2}$, while collective capitalist had already achieved the condition reformation of competition between the contractor enterprises in the public works' Market. As a result, the announced project is contracted by that capital, which made an offer nearest to $X_{2}$ against the other candidates, i.e., the potential contractors who participate in the auction. Thus, it is proven de facto that the collective capitalist shaped the competition conditions such a way that in each auction this contractor was selected among candidates who had a higher degree of productivity, distribution of work, etc. On the other hand, collective capitalist focused on constructive capital, which mainly was insisted on basing its profitability on appropriation of absolute surplus value. He decreased its project undertaking probability (Metallinos, 2011).

\subsection{Case of Tender Documentation budget equation of a public project with the mean social for private ones, increased by the algebraic price of their difference: $X_{1}=X_{2}+x^{\prime}{ }_{1}$}

Conditions:

$$
\begin{aligned}
\left(x_{1}, x^{\prime}{ }_{1}\right)=\left(0, x^{\prime}{ }_{1}\right) \rightarrow X_{1}=X_{2}+x^{\prime}{ }_{1} \quad: \quad & X_{1}=\left[X^{*}+(C . P .)+\text { taxes }\right] \\
& X^{\mathrm{d}_{1}}=X_{2}+x^{\prime}{ }_{1} \\
& X_{1}=X^{\mathrm{d}_{1}}+x_{1} .
\end{aligned}
$$

It is possible that the discount is equal to zero or in general $\lim _{x_{1} \rightarrow 0^{+}} x_{1}=0$. This means that contractual value in money $\mathrm{X}^{\mathrm{d} 1}$ is equal to Tender Documents Budget $\mathrm{X}_{1}$. This corresponds to either very low prices of Ministry's Lists Activities (Metallinos, 2011, p. 72) or in distorted centralisation or in project direct assignment without negotiation between purchaser-public authority and sellercontractor, or in the predominance of particular oligopoly in public works market. Via competition in market, this particular oligopoly has achieved the conditions of reproduction of total circulation of construction capital. First condition eliminates probability of substitution absolute by relative surplus value by the contractor. The 
second situation results in the practice, which was applied during the period of enforcement of Law 2576/98.

Consequently, keeping in mind those which are reported in (Metallinos, 2011, ch. 3, § 6.7) and in the documentation of (Metallinos, 2012) equation (6), we conclude that the submission of a null discount allows the candidate contractor to appropriate an extra rate of profit regarding the social mean, which he would appropriate if the project were manufactured for an individual. The price of this extra profit is increased as long as the Budget price of Auction Copies is increased in relation to $X_{2}$.

Hence, for one more time those conclusions have been verified, which concern the expedience of enactment of Law 2576/1998 and Law 3263/2004 (Metallinos, 2013b).

With regard to Law 2576/98, the practice application of distorted centralisation, to which medium-sized and in particular small-sized constructors' enterprises resorted because of the competition which they executed against the hegemonic construction companies of public works' sector, helped them protect, or even increase their rate of profit against the mean rate of profit of centralised companies members of large constructors' group in the period from 1998 to 2004. The measurement of construction cost using the Price Analysis deterred the reallocation of shares as an increase in $x^{\prime}{ }_{1}$ was equivalent to an increase in

$Y_{+}\left(=x+\Omega_{x 1}=x^{\prime}{ }_{1}+x^{\prime \prime}+\Omega_{x 1}=\left[X+\Omega_{x 1}\right]-X_{2}\right)$ and, as a result, to an increase of share of the national distribution of work which was appropriated by the small-sized constructors' enterprises. This specific share of the national distribution of work was developed for the defence of their reproduction in their competition among themselves and particularly the medium-sized constructors and the large construction companies to a lesser extent, because this way an increase in their capital degree of concentration was ensured.

On the contrary, the enactment of Law 3263/2004 cancelled the defence possibility of crystallized mean rate of profit by small-sized constructors, during the period of 1998-2004 because of mathematical method lifting and of Price Analysis replacement by Standard Item Lists (Metallinos, 2013b).

Besides, the discount biggest price equals the biggest quantity of relative surplus value which can be appropriated by a contractor because of his productivity, technical distribution of work, know-how etc. Moreover, the harder competition is among candidates, the more value $x_{1}$ is deducted by $X_{1}$. This is due to increased productivity of work etc. which they believe that they allocate, relating to their competitors. They are willing to "sacrifice" a quantity of absolute surplus value. They aim at the substitution of this quantity by that quantity of relative surplus value, which is ensured by their way of work (Metallinos, 2011). Thus, if technical oligopolies reduce $X_{1}$ and have possibility of submission of even null discounts $\left(\lim _{x_{1} \rightarrow 0^{+}} x_{1}=0\right)$ they have comparative advantage against their competitors because their profitability is based on their modernised capital, in their up-to-date knowhow etc. It is presupposed that $T_{2}$ remains stable $\left(\Omega_{x 1}=0\right)$.

This way, in public works' sector, such conditions are formed so that for the substitution of absolute surplus value by a relative one, it is a prerequisite that is usually called "modernisation" of companies. In contrast, the previous practice 
favoured the medium-sized and particularly small-sized construction companies, which continue to be included in the delayed part of Hellenic capital (Ioakimoglou, n. d., p. 36, p. 41).

\subsection{Typical contract case: $X_{1}=X_{2}+\left(x_{1}+x_{1}^{\prime}\right)$}

Conditions:

$$
\begin{aligned}
\left(x_{1}, x^{\prime}{ }_{1}\right)=\left(x_{1}, x^{\prime}{ }_{1}\right) \rightarrow X_{1}=X_{2}+\left(x_{1}+x^{\prime}{ }_{1}\right): \quad & X_{1}=\left[X^{*}+(C . P .)+\text { taxes }\right] \\
& X^{\mathrm{d}_{1}}=X_{2}+x^{\prime}{ }_{1} \\
& X_{1}=X^{\mathrm{d}_{1}}+x_{1} .
\end{aligned}
$$

The last case of the study object corresponds to design budget of typical public work. In this case, the model in question is developed in detail. Each parameter has an algebraic value other than zero. The case of zero price has already been studied, for each corresponding case. Of course, this may be either positive or negative. Concerning a negative discount case, it is obvious that

$$
X^{\mathrm{d}}{ }_{1}>X_{1}-\left(-x_{1}\right)
$$

This corresponds to under-costed equivalents in money of project activities. It turns out that designer did not take into account objective market prices. Experience confirms this when it happens.

Conversely, concerning a case of parameter $x_{1}^{\prime}$, it is extremely rare to have a negative value. However, in such a case, we have

$$
X_{2}>X^{\mathrm{d}}{ }_{1}-\left(-x^{\prime}{ }_{1}\right)
$$

It appears that the contractual budget is less than the equivalent of the same project if it was constructed on behalf of an individual private purchaser.

\section{CONCLUSION}

The study of the mathematical model of measuring the objective cost of a public project as it was developed and presented in the manuscript substantiates a different perception in relation to the prevailing practice in the secondary sector of the economy, in general. Construction experience has emerged as the critical condition for determining the objective algebraic price of production cost and purchase cost of each infrastructure technical project. Therefore, the specific equivalents in money are not calculated only one way. Conversely, a large number of individual 
conditions for the unobstructed execution of technical works and supply raw materials determine each time a different price for both production costs and market equivalent in money, if they are confirmed on the spot, whenever they occur.

In any case, in this article, we have focused on the mathematical model development we support by specifying the parameters that contribute to the divergence of budget algebraic prices between public and private projects. This occurs as a result of a competition in market among contractors in which collective capitalist intervenes in order to shape its execution conditions in market in accordance with his criteria. As a result, contractor's movement between the two sectors of the branch is prevented, and also the transfer of resources between them is prevented; particularly workers. The first case results in variations in the size of discount. The second case results in variations in the size of the design budget.

In addition, the suggested measurement of mathematical cost model of public work and the conclusions made can be exploited in the further study related to a critical evaluation between Earned Value Management Method and Earned Schedule Method, developing the dynamics of the model.

\section{REFERENCES}

Ioakimoglou, I. (n. d.). Reformation and International Specialization of Greek Industry. Institute of Work National Workers' Union of Greece.

Metallinos, P. (2012). Measurement of the Cost of a Public Works Project: The Case of Greece. European Journal of Law and Economics, 37(3), 517-527. https://doi.org/10.1007/s10657-012-9353-0

Metallinos, P. (2013a). Expanded Oligopolization of the Greek Public Works Market through the Framework of Law. Journal of Legal Affairs and Dispute Resolution in Engineering and Construction, 5(2), 86-89. https://doi.org/10.1061/(asce)la.1943-4170.0000105

Metallinos, P. (2013b). Application of Mathematical Method in Public Works Tendering in Greece. European Journal of Law and Economics, 35(3), 397-407.

Metallinos, P. (2011). Public Works Management: Costing Policies and Legislative Study (Diaxirisi Dimosion Ergon-politikes kostologisis kai meleti nomothesias). Tziolas editions, Thessaloniki: Jiaola.

European Commission. (2010). Europe 2020: A Strategy for Smart, Sustainable and Inclusive Growth. COM (2010) 2020 final.

The European Parliament and the Council of the European Union. (2014a). Directive 2014/23/EU of the European Parliament and of the Council of 26 February 2014 on the Award of Concession Contracts.

The European Parliament and the Council of the European Union. (2014b). Directive 2014/24/EU of the European Parliament and of the Council of 26 February 2014 on Public Procurement and Repealing Directive 2004/18/EC.

The European Parliament and the Council of the European Union. (2014c). Directive 2014/25/EU of the European Parliament and of the Council of 26 February 2014 on Procurement by Entities Operating in the Water, Energy, Transport and Postal Services Sectors and Repealing Directive 2004/17/EC. 
Law 4412/2016 on Public Contracts of Projects, Procurements and Services (adaptation to Directives 2014/24/EU and 2014/25/EU).

\section{AUTHORS' SHORT BIOGRAPHY}

Pavlos Metallinos has a PhD in Construction Economics and Construction Economic Management. $\mathrm{He}$ is a Civil Engineer with the Region of the Ionian Islands in Greece. He has a wealth of experience in public works construction acquired both as a Supervising Engineer and as Head of the Technical Services Division. He has worked as Adjunct Professor at the Civil Engineering Department of the University of Thessaly, Greece and belongs as an Adjunct Professor to the staff of the "Technical Works Management" M. sc. Program of the Hellenic Open University, Greece. His scholarly works have been published in Greek and international journals. Communication via email: kpaulosm@netscape.net.

ORCID iD: https://orcid.org/0000-0002-2039-6140 